\title{
Triguna and Anger in Adolescent
}

\author{
Dr. Soni Kewalramani ${ }^{1 *}$
}

\section{ABSTRACT}

One of the ways to study personality in Indian psychology through concept of Triguna. When three gunas are balanced the personality is balanced but if there is disturbance in any of the three gunas their personality gets disturbed. Triguna talks about three gunas Sattva (Purity knowledge,), Rajas (Anger, Action) Tamas (Laziness, apathy). The emotions we experience are closely related to the dominant guna in us. And therefore, another concept studied is that of anger. State anger is a subjective emotion accompanied by muscle tension and stimulation of the autonomous nervous system; its intensity may deviate from quite mild to quite strong. However, Trait anger is perceived in far more situations as displeasing and frustrating, and accordingly it is described as a tendency to have rather frequent state anger.

The main purpose of the present research is to see the relationship between Sattva, Rajas, Tamas and State and Trait anger, gender difference on Sattva rajas Tamas and State and Trait anger are also studied. Sample size of 100 was taken. Incidental sampling techniques was used. It is an exploratory research.

Results showed that there was a positive relationship between Triguna and Anger -Sattva guna and State and Trait anger, Rajas guna and State and Trait anger, Tamas guna and State an Trait anger. Gender on basis of guna and anger result reveals that there was no significance difference between boys and girls on the basis of guna and anger.

Keywords: Triguna, State and Trait Anger

In the present age of globalization and constant rush, the need of the hour is to understand human behaviour through a theory of personality that transcends this crisis of cultural and racial bias to propound one that is valid across the world. For this, the basic condition is that it should be acceptable across the world, be of a fundamental nature, and valid to people across all genres. To understand this, the first source of knowledge that comes to mind to deal with the problem at hand is that of the Indian philosophical systems that have withstood the test of time to be applicable across millennia without losing their importance and applicability to people from ages

\footnotetext{
${ }^{1}$ Assistant Professor, Amity University Uttar Pradesh, Lucknow Campus

*Responding Author

(C) 2016 I S Kewalramani; licensee IJIP. This is an Open Access Research distributed under the terms of the Creative Commons Attribution License (http://creativecommons.org/licenses/by/2.0), which permits unrestricted use, distribution, and reproduction in any Medium, provided the original work is properly cited.
} 
to the present day. One of the ways to study personality in Indian psychology is through concept of Triguna,

The present condition has also resulted in more experience of one emotion- anger. Anger is an emotional state. It is emotion made in response to irritation or destruction. Anger is an emotional-physiological-cognitive internal state; it is separate from the behaviour it might prompt Anger becomes a problem when it becomes too strong, happens too often, lasts too long, spoils relationships at work and in particular if it leads to violence or aggression. Anger is displayed when one is criticized, embarrassed, underestimated, or ignored and perceive such situations as threats.

Since adolescence is a period in which there are dramatic changes being made and as a result of such changes an individual's perception of the world is changed, it becomes important to study the dominant guna in them and to see how the guna relates to anger in adolescence. It may have negative effects on personality which is likely to turn into emotions like hatred, grudge, jealousy and hostility.

\section{Theory of Triguna}

According to the Samkhya Philosophy, all human beings are composed of three gunas or qualities and the excess of any one of these qualities determines our psychophysical nature.

From a psychological standpoint, the three gunas might be considered as the three fundamental components of the human mind. (Kulkarni, 1972), as the tendencies exhibiting themselves at different levels of consciousness (Pathak, 1932), or as the three aspects of human temperament and personality (Boss, 1966, Parameswaran, 1969, Smart 1964).

\section{DESCRIPTION OF THE GUNAS}

(A) Sattva - Sattva is the quality of intelligence, virtue and goodness and creates harmony, balance and stability. It is light (not heavy) and luminous in nature. It possesses an inward and upward motion and brings about the awakening of the soul. It is nearest to nature since it is 'natural' to expand, evolve and grow.

They involve themselves in activities that cater to the development and expression of the intellect, mind and spirit. They have mild desires and strong will. They are capable of initiating and carrying out any intellectual or meditative action (Malhotra, 2001). Their hearts expands to humanity and they can keep larger interest in mind and sacrifice personal happiness. Initiative and leadership come naturally to them (Kapadia, 2004). Their actions have a clear direction and purpose, focus is sharp, the person is calm and composed (Balachandran, Raja and Wair, 2003).

They are highly integrated and at peace even in midst of most gruelling work. They execute serenity, compassion, transparence even while being great achievers (Chakraborty, 1998). 
They see work as rewarding by itself, to be done without desire, hatred or attachment. They perform their duties with enthusiasm determination and earnestness and do not lose their sense of equanimity even if the work does not succeed in its objective (Balachandran, Raja and Wair, 2003). They are full of patience (Chatterjee, 1987).

(B) Rajas - Rajas is most active of the gunas and its characteristics are motion, stimulation and overcoming resistance. Rajas is the quality of change, activity, and turbulence. It possesses outward motion and causes self-seeking action that leads to fragmentation and disintegration. It is the force of passion that causes distress and conflict. Rajas has the inspirational tendency. Depending on our inclination towards Sattva or Tamas, Rajas prompts us to action.

Rajasic minds are usually agitated and seldom at peace. Emotionally insecure, they vitiate between love and hate, happiness and unhappiness. Impatience and impulsiveness are the weaknesses, they do not forgive easily (Kapadia, 2004). Being critical, they remember wrong doings and forgets good acts of others. These two tendencies intensify negativity towards others extending to the limit of hatred and cause disturbance in the mind. According to Kejriwal and Krishnan (2004), the intellect of the rajasic decides erroneously between right and wrong action, fear and fearlessness, bondage and liberation. What seems vain to sattvics, comes naturally to rajasic - self-praise, cruelty, ruthlessness, intolerance, envy, sharp reactions and passion (Kapadia, 2004). They are more extroverted and high in ego-libido (Ranchan, 1987).

According to Chaturvedi (1991), rajasic craves to get the best and all for himself. He may adopt even illegal ways to obtain his sense gratification. Rajasic people prefer food that is violently bitter, sour, salty, hot, pungent, acidic and burning. Such food causes pain, bitterness, ill-health and distemper of mind and body (Kejriwal and Krishnan, 2004). They are restless and active and have a need for power. They are achievement oriented (Kapadia, 2004). They make big plans and starts activity with excitement consuming too much prana which quickly drains them out.

(C ) Tamas - Tamas is the quality of dullness, darkness or veiling or obstructing in its action. It functions as the force of gravity that retards things and holds them in specific limited forms. It possesses a downward motion that causes decay and disintegration.

Tamasics have disturbance in the process of perception and activities of the mind. They have deep rooted psychological blockages. They have delusions and false knowledge. Their energy and emotions tend to be stagnant and repressed, and they do not know what their problems really are. For them, the materialistic world that can be enjoyed by the sense is the only reality. This makes them down to earth and practical but at the same time lacking finer higher qualities (Kapadia, 2004). Tamasic types are neither into the reflectivity of the sattvic 
types nor into the action of the rajasic type. They are into themselves, languor and lassitude, they are uninvolved (Ranchan, 1987). The conscious is so thickly wrapped in ignorance that it makes wrong for right and sees everything distorted (Kejriwal and Krishnan, 2004).

A tamasic is lazy, morose, procrastinating, willing to cheat (Balachandran, Raja and Wair, 2003). He has no concentration of mind and is of immature knowledge. He is arrogant, deceitful and prone to harm others for securing his own selfish ends. He is given to mental depression (Chatterjee, 1987). The tamasic type is callous about his duty. He wastes his time without any guilt. He yearns neither to learn nor to work. He yields to lethargy and sleep. Darkness of the mind leads him to headlessness, indiscrimination and delusion. He will not take any initiative or action (Elankumaran, 2004). Tamasic abandon their allotted task due to delusion (Kejriwal and Krishnan, 2004). They are lazy and dull in their work (Chakraborty, 1998).

\section{Anger- State and Trait}

Anger is defined in two terms according to Spielberger (1991) State anger is a subjective emotion accompanied by muscle tension and stimulation of the autonomous nervous system; Its intensity may deviate from quite mild to quite strong. However, Trait anger is perceived in far more situations as displeasing and frustrating, and accordingly it is described as a tendency to have rather frequent state anger.

Emotion is a state of the individual which deprives him of his stability. It is a distressed and muscular activity. Emotion is a state of the individual in which the body is externally as well as internally very upset. Anger is one of the six basic human emotions along with sadness, fear, surprise, disgust and happiness. It is related to one's psychological interpretation of having been affronted, wronged, or denied and a tendency to react through retribution.

According to Spielberger (1991), anger consists of two components: State anger and Trait anger.

\section{State Anger}

According to Spielberger-(1999) "State anger is defined as a psychobiological, subjective experience that, over time and across situations, usually refers to an emotional state that involves displeasure and consists of subjective feelings that vary in intensity, from mild irritation or annoyance to intense fury and rage”' (Spielberger, et al., 1983, 1995; Goozen Van et al., 1994).

\section{Trait Anger}

According to Spielberger (1999)-Trait anger which defined in terms of individual differences in the disposition to perceive a wide range of situations as annoying or frustrating and by the tendency to respond to such situations with elevations in state anger. "It is tendency to react angrily to perceived situation”. It evaluates a person's general predisposition to become angry. It 
measure how angry feeling are experienced over time whether people have an overall angry or hot headed temperament ( $T$-Ang/T), or whether people tend to respond with anger when they feel they are being treated unfairly or being criticized by others $(T-A n g / R)$. Trait anger is described as a dispositional feature where frequent anger is experienced, with varying intensity and is often accompanied by related negative emotions.

\section{REVIEW OF LITERATURE}

Review of literature suggests that attempts to study Triguna and Anger separately are many but to the best knowledge of the researcher, there are no empirical researches relating the two.

Researches on Triguna

Mohan and Sandhu (1986, 1988) developed Triguna personality inventory (TGPI) on the basis of the Gita tyopology that measures the three Gunas separately with one being predominant. Researcher concluded that Sattva is different distintinctly from Rajas and Tamas.

Narayanan and Krishnan (2001) had measured the three Gunas along ten dimensions that is attribution, leisure, food, interests, praise and criticism, sympathy, right and wrong, working with determination, motivation to work, and accepting pain. Result found that the Sattvic dimensions enhanced transformational leadership and Rajasic dimensions reduced the Karma.

Sebastian and Mathew (2002) have also found that PSI (performance studies international) experience was positively related to Sattva and Rajas for females

Paranjpe (2004) considers jiva, svabha and prakrti, ahamka, and Atman and Purus as the most important concepts related to personality and self, which can help in developing indigenous personality.

Kewalaramani S. (2006) Emotional Intelligence was correlated with Triguna. Result shows that Emotional Intelligence is positively correlated with Sattva and negatively with Tamas.

Studies was done by Shilpa \& Murthy, (2011) They found that the General Adult group has higher values for both Rajas and Tamas, while Teacher group has higher value for Sattva and least values for Rajas and Tamas. This also indicates that where Sattva is high, Rajas and Tamas are low and vice versa.

State/ Trait anger-Researches have been done which relates trait and state anger to Personality, Relationship, Clinical, and Self Efficacy.

Ozelliği K, Ozyesil Z (2012) conducted a study and found that five factor personality traits (neuroticism, extraversion, openness to experiences, agreeableness and conscientiousness) predicts trait anger. 
Kırımoğlu H, Yıldırım Y, Temiz A (2010) -The aim of this research was to investigate the state of trait anger-anger expression and friendship commitment between genders (Boys and Girls).Result reveals that boys had higher scores of internal and external anger and scores of friendship commitment than girls.

Arslan $C$ (2009) used a study model with 499 students between 16 and 18 years of age to investigate associations between perceived social support, self-esteem, trait anger, and anger expression. Result reveals that there was a significant negative relationship among anger expression and the social support and trait anger perceived from family and teachers, and between self-esteem and trait anger.

Review of literature suggests that Theory of Triguna has not been studied with relation to AngerState and Trait. There have been no attempts to study this relationship in adolescents.

\section{Problem:}

The main purpose of the present research is to see the relationship between Sattva, Rajas, Tamas and State and Trait anger, Gender difference on Sattva rajas Tamas and State and Trait anger are also studied.

\section{OBJECTIVES}

1. To study the relationship between Triguna and state and trait anger

2. To study the gender difference on Sattva, Rajas Tamas and State and Trait anger.

\section{Assumption:}

- Sattva guna is negatively correlated with Trait anger.

- Sattva guna is negatively correlated with State anger

- Rajas is guna positively correlated with Trait anger.

- Rajas is guna positively correlated with State anger

- Tamas guna is positively correlated with State anger.

- Tamas guna is negatively correlated with Trait anger.

- Boys will be higher in Trait anger than girls.

- Girls, will be higher in State anger than boys.

- Rajas guna will be more dominant in boys than girls.

- Tamas guna will be more dominant in boys than girls.

- Sattva guna will be more dominant in girls than boys.

The above assumptions have been made on the basis of theoretical understanding of Theory of Guna and State and Trait Anger.

\section{Variables:}

- Anger -State anger- It is defined as a psychobiological, subjective experience that, over time and across situations.

- Trait anger -It is tendency to react angrily to perceived situation”. 
- Triguna-

Sattva- Purity, Knowledge, kind calm.

Rajas -Creation, action, impulsive, aggressive.

Tamas- Ignorance, destructive, depressive, violence, tendency to steal.

- Gender (Boys and girls)

\section{Locale of the study:}

$\checkmark$ Sample size- 101 sample size is being taken.

$\checkmark$ Sample Selection- Sample was collected from University students age group- 17-19 years

$\checkmark$ Sample Technique-Incidental sampling is being used.

$\checkmark$ Research Design-It is an exploratory research, Correlational in nature.

\section{Research tools used:}

The tools used to conduct the study and collections of data are as follows:-

\begin{tabular}{|l|l|l|}
\hline $\begin{array}{l}\text { Psychological test \& tools } \\
\text { State \& Trait anger (STAS) inventory }\end{array}$ & $\begin{array}{l}\text { Developed by } \\
\text { Spielberger }\end{array}$ & $\begin{array}{l}\text { Year } \\
1985\end{array}$ \\
Vedic personality inventory & Wolf, D.B. & 1998 \\
\hline
\end{tabular}

- Description of the research tools:- State \& Trait anger inventory:.

State \& Trait anger (STAS) inventory propounded by Spielberger. The 30 items that make this instrument assess anger both as emotional state that varies in intensity \& as relatively stable personality trait.

Reliability- Internal consistency reported for the 10 items forms It ranges from .87-.93.All internal consistency result are based on cronbach's alpha.

Validity-Concurrent validity support is evidence by correlation.

\section{- Vedic Personality Inventory:}

Vedic Personality Inventory was propounded by David B. Wolf .It was devised to assess validity of the Vedic concept of the three gunas. There are 56 items which are derived from Vaisnava. According to Vedic experts these 56 items are comprised of 15 for sattva, 19 for rajas, 22 for tamas.

Reliability- Each guna constitute a subscale and internal reliability for each subscale was measured using cronbach's alpha. Alpha for sattva scale was .866, Alpha for rajas scale was.928, Alpha for tamas scale was.910, after removal of items.

Validity- Convergent Construct validity - It has been assessed by correlating the subscales with existing scales measuring life satisfaction and verbal aggressiveness.

Factorial validity-Indicates extent to which an item correlates with the subscales with which it is intended as compared to other subscales. 


\section{Procedure}

Previous appointment was taken from the students to fill Questionnaire related to personality and anger. The two tests were administered together. Instructions were clearly given to the participants.

\section{Data Analysis}

Pearson product moment correlation was done to find relationship between Triguna (Sattva, Rajas, Tamas) and anger (state and trait) t-test was calculated to study gender difference on state and trait anger and sattva, rajas, tamas dominance in boys and girls.

\section{ANALYSIS OF RESULT}

The main purpose of the analysis is to see the relationship between Sattva, Rajas, Tamas and State and Trait anger, Gender difference on sattva rajas tamas and state and trait anger are also studied.

Relationship between Triguna and State and Trait anger- The following table shows the relationship between Triguna and Anger-

Table 1 showing correlation between Triguna and Anger

\begin{tabular}{|l|l|l|l|}
\hline & Sattva Guna & Rajas Guna & Tamas Guna \\
\hline State Anger & .52 & .42 & .58 \\
\hline Trait Anger & .44 & .36 & .47 \\
\hline
\end{tabular}

\section{Sattva and State Anger}

The value $\mathbf{5 2}$ signifies that there is a positive and substantial correlation between sattva guna and state anger. There is a significant correlation between sattva guna and state anger which means that dominancy of sattva guna is related with state anger positively. The features of sattva guna -calmness, praise, lightness, may have a calming effect on individuals and as a result they get angry as per situation and not all the time. Anger does not become a trait of their personality. This relationship is in accordance with Theory of Guna.

\section{Sattva and Trait Angers}

The value $\mathbf{. 4 4}$ signifies that there is a positive and substantial correlation between Sattva guna and Trait anger. Those individual in whom sattva guna is dominant in them mainly Trait anger is higher. The quality of sattva guna and trait anger is opposite sattva being calm and controlled and trait anger being chronic. The theoretical understanding of the two concept relates them negatively but empirical data of the present research related the two positively .This needs further probing. 


\section{Rajas Guna and State anger}

There is a positive correlation between Rajas guna and state anger $\mathbf{. 4 2}$, which means that there is a positive relation between Rajas guna and State anger. An individual in whom Rajas is dominant state anger is higher. As those individual in whom rajas is dominant they have rajasic features such as- creation, action, attraction, wilful, manipulative, intense activity, which are related with the features of state anger as envy, resentment, hate, disgust. It may be because at this age each individual have their goal to achieve where they may need to please other to achieve their goal .For this they need to control their anger. By this their anger becomes state anger rather than biological anger.

\section{Rajas Guna and Trait anger}

There is a positive correlation between Rajas guna and Trait anger . $\mathbf{3 6}$ low, Rajas guna makes an individual to do an activity. The relationship, though positive is low. Rajas guna have features of anger, aggression, impulsiveness, and this relates directly with trait anger which has features such as hate, disgust, envy, resentment, a biological anger which persist as a part of personality. Though there are so many similarities and theoretically they seem to be highly correlated, the present research shows a positive and low relationship between the two.

The important point to take into consideration is that rajas is positively related to both state and trait anger. This shows that these individual in whom rajas is dominant anger is present whether situational or biological. This goes with the theoretical base of the two concepts also.

\section{Tamas Guna and State Anger}

There is a positive correlation between Tamas guna and State anger .58, these individual with dominant tamas guna as higher on state anger. As an individual with dominancy of Tamas guna have features of Tamasic guna such as laziness, apathy, grief , loneliness, depressive, which makes a person to be there in their own life and not care for anything about their career, their health, their work they do not bother about anything. The individuals with these features they do not have the any cause to get angry every time because they live their own life and thus they do not get angry at anytime. If at all they get angry it is a per situation and thus a positive relation is found between Tamas and state anger.

\section{Tamas Guna and Trait Anger}

There is a positive correlation between Tamas guna and Trait anger .47, which means that with dominancy of tamas guna, trait anger increases. The feature of tamasic guna as destructive, violence, hate, criminality, stealing, the characteristics of Tamas guna may have its influence on an individual display of anger and thus the correlation of Tamas is high with Trait anger. Still relationship is not as high as that of Tamas and State anger which shows that dominance of Tamas guna has a more positive relationship with situational anger i.e. state anger. 
An impotant point here is regarding relationship of Sattva and Tamas with Trait anger. Both Sattva and Tamas guna have features which may seen similar at surface level like not setting angry but the reason underlying them are totally different. When Sattvic individual is not angry biologically (i.e. trait anger) because of purity of heart and calmness of mind whereas the reason for Tamasic not getting angry biologically (i.e. trait anger) are laziness and lethargy and lack of will to o anything. Thus the relationship seems similar but underlying reason make the two Sattvic and Tamasic extremely different from one another.

To conclude, the study shows that Sattva is also positively related with anger. This is an interesting and unexpected finding. One possible explanation for this could be that the reason why Sattvic people get angry may be different from situations which arise anger in Rajasics or Tamasics. The current study did not involve collection of data regarding cause of anger which might have helped in understanding this relationship. For future researches, it is advised to take cause of anger also to understand this relationship better.

Gender Differences on Anger- The following table shows the gender differences obtained on anger-

Table 2, Gender difference on State Anger

\begin{tabular}{|l|l|l|l|l|}
\hline & Mean & Standard Deviation & t-value & $\mathbf{P}$ \\
\hline Boys & 29.17 & 29.31 & .18 & $<.05$ \\
\hline Girls & 28.08 & 29.31 & .18 & $<.05$ \\
\hline
\end{tabular}

The mean score of boys was 29.17 and mean score for girls was (28.08)

The table show that boys and girls do not differ significantly on state anger. Means direction shows that boy have higher state anger than girls but the difference is too small to be significant. Generally boys are said to be more violent and angry as compared to girls but the present study does not show this difference. One of the reasons could be that with changed condition, girls are expressed to environment similar to boys and thus they may show anger in similar manner. The present sample is also of University which mainly represent the upper class metro thinking adolescents and this may have its effect on the results.

Table 3, Gender Differences on Trait Anger

\begin{tabular}{|l|l|l|l|l|}
\hline & Mean & Standard Deviation & t-value & $\mathbf{P}$ \\
\hline Boys & 34.72 & 9.76 & .84 & $<.05$ \\
\hline Girls & 33.04 & 9.76 & .84 & $<.05$ \\
\hline
\end{tabular}

The mean score of boys was 34.72 and of girls mean value 33.04

With regarding to trait anger also, the t-test was not significant. This means that boys and girls do not differ significantly on trait anger. The reason for Trait anger may also be similar to that of state anger. 
Gender difference between Sattva, Rajas, Tamas- Table 4 shows gender differences between Sattva, Rajas and Tamas.

Table 4 Showing gender difference on the basis of guna

\begin{tabular}{|l|l|l|l|l|l|}
\hline & Mean & Mean & Standard Deviation & t-value & P \\
\hline & Girls & Boys & & & \\
\hline Sattva & 40.2 & 37.4 & 14.84 & .929 & $<.05$ \\
\hline Rajas & 33.5 & 33.9 & 16.65 & 1.18 & $<.05$ \\
\hline Tamas & 26.1 & 28.5 & 9.26 & 1.27 & $<.05$ \\
\hline
\end{tabular}

Sattva- The mean score of girls was 40.2 and of boys mean value (37.4) for Sattva guna. The table show that boys and girls do not differ significantly on sattva guna. Means direction shows that girls are higher on sattva guna but the difference not statically significant. General perception is that girls may be higher on Sattva guna but the results are not significant. A reason may be that today girls are exposed to similar environment as that of boys and this may a reason for these results.

Rajas-The mean score of girls was 33.5 and of boys mean value (33.9) for Rajas guna. The table show that boys and girls do not differ significantly on Rajas guna. Generally boys are said to be more violent and angry as compared to girls. And as the rajas guna related to anger and activity who are preconditions boys' mainly arrogant, impulsive, anger personality were assumed to higher on rajas but the present result do not show this gender difference on rajas.

Tamas-The mean score of girls was 26.1and of boys mean value (28.5) for Tamas guna. The table show that boys and girls do not differ significantly on Tamas guna. Means direction shows that boys have more dominant tamas guna than girls. But the difference is not significant. Overall in the present study, gender differences were not found on sattva, rajas, tamas.

\section{CONCLUSION}

Researcher's aim was to find the relationship between Triguna (Sattva, Rajas, Tamas ) and Anger (State and Trait anger). Result reveals that there is a positive relation between Triguna (Sattva, Rajas, Tamas) and anger (State and Trait anger).

Sattva guna is positively related to State anger. The features of Sattva guna -calmness, praise, lightness may have a calming effect on individuals and as a result they get angry as per situation. But the relationship of Sattva guna with Trait anger needs probing because quality of Sattva guna and Trait anger are opposite Sattva being calm and controlled and Trait anger being chronic these two concept relates negatively. 
Rajas guna is positively related with State anger and Trait anger. Those individual in whom rajas is dominant the Rajasic features such as- creation, action, attraction, will have its effect on the features of state anger as envy and resentment.

Tamas guna is positively highly related with state anger. Those who have features of Tamasic guna such as laziness, apathy, grief are self centred and are not concerned about their career and health as it requires efforts and they lack the zeal to act. The individuals with these features do not have the any cause to get angry every time because they live their own life and thus they do not get angry every time.

Gender difference on anger- Boys and girls do not differ significantly on state and Trait anger. Means direction shows that boy have higher state anger and Trait anger than girls but the difference is too small to be significant. Mainly boys are said to be more violent and angry as compared to girls but with the sample of the present research is taken from a University located in a city and the girls from this kind of background are more exposed to similar environment as that of boys. This may be one of the reasons for the results in the study.

Gender difference on guna- Result reveals that boys and girls do not differ significantly on sattva guna, Rajas guna, Tamas guna. Means direction shows that girls are higher on sattva guna, boys on Rajas guna and Tamas guna but the difference not statically significant.

\section{REFERENCES}

Arslan, C. (2009). Social behaviour and personality. Anger, Self-Esteem and Perceived Social Support in Adolescence. Volume (37) Number (4). Email coskunarslan@selcuk. edu.tr.

Balachandran S., Raja, K.C.R. and Nair, B.K. (2003), Ethics, Indian Ethos and Management, Shroff Publishers and Distributors Pvt. Ltd.

Boss (1966), Parameswaran, (1969), Smart (1964), In Rao, P.V. Krishna and Harigopal, K. (1979), The Three Gunas and ESP : An Exploratory Investigation, Journal of Indian Psychology, Vol. 2, No. 1, 63-67.

Chakraborty, S.K. (1998), Foundations of Managerial Work - Contribution From Indian Thought , Himalayan Publishing House.

Chakraborty, S.K. (1998), Foundations of Managerial Work - Contribution From Indian Thought , Himalayan Publishing House.

Chatterjee, A.K. (1987), The Gita and its Culture, Sterling Publishers Private Ltd.

Elankumaran, S. (2004), Personality, Organizational Climate and Job Involvement : An Empirical Study, Journal of Human Values, 10:2, 117-130.

Kapadis, Mala (2004), Emotional Intelligence- A Workbook for Beginners, BPI (India) Pvt. Ltd.

Kejriwal, Aditi and Krishnan, Venkat R. (January-March, 2004), Impact of Vedic Worldview and Gunas on Transformational Leadership, Vikalpa: The Journal for Decision Makers, Volume 29, No. 1, 29-40. 
Kewalramani, S. (2006), Emotional Intelligence and Triguna in Management : An Action Research, Ph.D. Thesis, Lucknow University, Lucknow.

Kırımoğlu. H, Yıldırım. Y and Temiz (2010). A International Journal of Human Sciences. A study on trait anger - anger expression and friendship commitment levels of primary school 2nd stage students who play - do not play sports. Volume (7) No (2) ISSN:1303-5134.

Kulkarni (1972), ), In Rao, P.V. Krishna and Harigopal, K. (1979), The Three Gunas and ESP : An Exploratory Investigation, Journal of Indian Psychology, Vol. 2, No. 1, 63-67.

Mohan and Sandhu (1988), In Pandey Janak (Ed.) (2001), Psychology in India Revisited Developments in the Discipline Vol. 2 - Personality and Health Psychology, Sage Publications India Pvt. Ltd., New Delhi.

Narayanan, Jayanth and Krishnan, Venkat R. (2003), Impact of Sattva and Rajas Gunas on Transformational Leadership and Karma Yoga, Journal of Indian Psychology, Vol. 21, No.2, 1-11.

Özelliği, K. and Özyesil, Z. (2011). Journal of Education and Science. Five Factor Personality Traits as Predictor of Trait Anger and Anger Expression. Volume (37) No (163).

Paranjpe, A.C. (2004). Handbook of Indian psychology. New Delhi, India: Cambridge University Press.

Pathak (1972), ), In Rao, P.V. Krishna and Harigopal, K. (1979), The Three Gunas and ESP : An Exploratory Investigation, Journal of Indian Psychology, Vol. 2, No. 1, 63-67.

Ranchan, Som P. (1987), New Sight on The Gita, Ajanta Publications

Sebastian and Matthew (2002), In Kejriwal, Aditi and Krishnan, Venkat R. (January-March, 2004), Impact of Vedic Worldview and Gunas on Transformational Leadership, Vikalpa: The Journal for Decision Makers, Volume 29, No. 1, 29-40.

Shilpa, S. and Murthy, C.G.V. (2012). Development and Standardization of Mysore Triguna Scale.http://sgo.sagepub.com/content/early. Email: shilpamhdatar@yahoo.co.in

Shilpa, S. and Murthy. C. G. V. (2012). Journal of the Indian Academy of Applied Psychology. Combination of Trigunas in Different Groups of People. Volume (38) No (3).

Spielberger (1883), From the site https://books.google.co.in/books?id=hXu0AAAAQBAJ

Spielberger (1999), From the site https://books.google.co.in/books?id=Jjjp3g4xUVcC

Wolf, David B. (1998). The Vedic Personalit6y Inventory: A Study of the Gunas, Journal of Indian Psychology, Vol. 16, No. 1, 26-43.' 